\title{
Quantitative Structure-Activity Relationship Study of Some Antipsychotics by Multiple Linear Regressions
}

\author{
Danica S. Perušković, Nikola R. Stevanović, Aleksandar Đ. Lolić, Milan R. Nikolić, \\ Rada M. Baošić \\ Faculty of Chemistry, University of Belgrade, Studentski trg 12-16, Belgrade, Serbia \\ Email: rbaosic@chem.bg.ac.rs
}

Received 28 February 2014; revised 2 April 2014; accepted 10 April 2014

Copyright (C) 2014 by authors and Scientific Research Publishing Inc.

This work is licensed under the Creative Commons Attribution International License (CC BY). http://creativecommons.org/licenses/by/4.0/

\section{Abstract}

The retention behavior and lipophilicity parameters of some antiphychotics were determined using reversed-phase thin layer chromatography. Quantitative structure-activity relationships studies have been performed to correlate the molecular characteristics of observed compounds with their retention as well as with their chromatographically determinated lipophilicity parameters. The effect of different organic modifiers (acetone, tetrahydrofuran, and methanol) has been studied. The retention of investigated compounds decreases linearly with increasing concentration of organic modifier. The chemical structures of the antipsychotics have been characterized by molecular descriptors which are calculated from the structure and related to chromatographically determinated lipophilicity parameters by multiple linear regression analysis. This approach gives us the possibility to gain insight into factors responsible for the retention as well as lipophilicity of the investigated set of the compounds. The most prominent factors affecting lipophilicity of the investigated substances are Solubility, Energy of the highest occupied molecular orbital, and Energy of the lowest unoccupied molecular orbital. The obtained models were used for interpretation of the lipophilicity of the investigated compounds. The prediction results are in good agreement with the experimental value. This study provides good information about pharmacologically important physico-chemical parameters of observed antipsychotics relevant to variations in molecular lipophilicity and chromatographic behavior. Established QSAR models could be helpful in design of novel multitarget antipsychotic compounds.

\section{Keywords}

Antipsychotics, Lipophilicity, Quantitative Structure-Activity Relationships, Reversed-Phase Thin Layer Chromatography 


\section{Introduction}

Chromatography is a powerful technique for the measurement of physicochemical properties that are used as parameters to correlate biological activities with structures in quantitative structure-activity relationship (QSAR) studies. QSAR modeling pertains to the construction of predictive models of biological activities as a function of structural and molecular information of compound library. These studies have had a tremendous impact in the fields of drug design, toxicology, and environmental monitoring. Typical molecular descriptors that are correlated to electronic properties, hydrophobicity, steric effect and topology, can be determined empirically through experimentation or theoretically via computational chemistry. Computationally determined property parameters have become crucial in identifying potential drug candidates [1]-[4].

Psychosis is a syndrome, which is part of a group of very serious mental disorders in which some loss of contact with reality has occurred. The symptoms of psychosis may be lessened by antipsychotic medications. Antipsychotics affect many neurotransmitter systems. Common causes of chronic psychosis in the elderly include: dementia, depression, delirium, Parkinson's disease, manic depressive illness, and schizophrenia [5]-[7]. Schizophrenia is the overwhelming mental disorder characterized by severe distortions of reality and disturbances in perception, intellectual performance, behaviour and motor activities. Various typical antipsychotics like chlorpromazine, haloperidol have been introduced which showed improvement in positive symptoms of schizophrenia by blocking dopaminergic transmission in the brain [8]. It is very important to control the antipsychotics distribution to the place of action. The lipophilicity has a significant impact on the absorption, distribution, metabolism, and excretion of compounds (ADME properties). Antipsychotics are targeting the central nervous system, so they must have certain lipophilicity to be able to pass the blood brain barrier by P-glycoprotein [9] [10]. Also, the gastrointestinal resorption and distribution of drugs through the bloodstream, by means of albumin, is dependent on lipophilicity [11]. The general rule is that the more lipid soluble a molecule or drug is, the more readily it will tend to enter the brain tissue [10].

In preclinical trials the determination of lipophilicity of potential drug (through either experimental measurement or prediction) is one of the first selection criteria. The classical procedure is the determination of lipophilicity in terms of $\log \mathrm{P}$ (the partition coefficient), which is descriptor of the differential partitioning of a neutral compound between two immiscible solvents, usually octan-1-ol and water [12]. Instead of this traditional shakeflask method, reversed-phase thin layer chromatography (RP TLC) is frequently used to estimate the lipophilicity of observed compounds due to the fact that the same basic intermolecular interactions determine the behavior of compound in both biological and chromatographic environment [13]-[17]. For this purpose the intercepts of the linear relationships between the logarithm of retention constants and the volume fraction of the organic modifier in a binary mobile phase obtained in RP TLC experiments are the most suitable. The relation is given by equation:

$$
R_{M}=R_{M}^{0}+m \varphi
$$

where $\varphi$ stands for the concentration of the organic component in the mobile phase and $m$ is the slope, which indicates the rate at which the solubility of the solute in the mobile phase increases with changes in its composition. Lipophilicity, measured as $R_{M}^{0}$, represents the relative affinity of different compounds for the non-aqueous environment in the biological system. $R_{M}^{0}$ is the value of $R_{M}$ in pure water, and therefore it could reflect the dependence of the hydrophobic properties of investigated compound on its structure.

Multivariate regression models in chemistry and other sciences quantitatively relate a response (dependent) variable $\mathbf{y}$ to a block of predictor variables $\mathbf{X}$, in the form of a mathematical equation $\mathbf{y}=f(\mathbf{X})$, where the predictors can be determined experimentally or computationally. Among the best known of such quantitative-X-y relationships is quantitative structure-activity relationships, in which $\mathbf{y}$ is a biological response and any of the predictors, designated as descriptors, may account for a microscopic (i.e., determined by molecular structure) or a macroscopic property. QSAR has become important in medicinal chemistry, pharmacy, toxicology and environmental science, because it deals with bioactive substances such as drugs and toxicants [18].

The objectives of this work were to investigate the retention behavior of this kind of compound using reversed-phase thin-layer chromatography, to determine their lipophilicity, to investigate the effect of different mobile-phase modifiers on the retention as well as on the lipophilicity parameter, and to estimate the quantitative structure-activity relationship using molecular descriptors. 


\section{Experimental}

\subsection{Chromatography}

Chromatographic investigations were carried out by horizontal thin layer chromatography on silica gel RP 18 plates, $10 \times 10 \mathrm{~cm}$ (Merck, Darmstadt, Germany) using a Camag horizontal HPTLC development chamber in the tank configuration. Standard solutions $(5 \mathrm{mg} / \mathrm{mL}$ ) of the compounds were prepared in chloroform. The plates were spotted with $1.0 \mu \mathrm{L}$ aliquots of freshly prepared solutions of the corresponding compound. Before development, the spotted plates were equilibrated for $30 \mathrm{~min}$ in a chromatographic chamber saturated with mobile phase vapor. All solvents used throughout the present study were of analytical-grade purity. The applied mobile phase was a mixture of different mobile-phase modifiers (acetone, tetrahydrofuran, methanol) and water. The concentration of organic modifier in the mobile phase ranged from $50 \%$ to $80 \%(\mathrm{v} / \mathrm{v})$ in $5 \%$ increments. The investigated compounds were chromatographed simultaneously. After development, the spots were colored by Dragendorff reagent. $\mathrm{R}_{\mathrm{F}}$ values were determined as averages from three independent measurements. All measurements were carried out at ambient temperature $\left(22^{\circ} \mathrm{C} \pm 2^{\circ} \mathrm{C}\right)$.

\subsection{Calculations}

All structures were drawn with the HyperChem Professional software (version 7.0, Hybercube, Gainseville, FL, USA). In order to obtain molecular descriptors; the geometry optimization of molecules was performed by the molecular mechanics MM+ force field method. The single point calculation was done with the semi-empirical quantum chemical method AM1. Polak-Ribiere algorithm with the convergence limit set at $0.1 \mathrm{kcal} / \mathrm{mol}$ was used during modeling process. The HyperChem was used to calculate Total energy $\left(E_{\text {Total }}\right)$, Dipole moment $(\mu)$, Energy of the highest occupied molecular orbital $\left(E_{\mathrm{HO} о}\right)$, Energy of the lowest unoccupied molecular orbital $\left(E_{\text {LUMO }}\right)$, Surface area (SA), Hydration energy $\left(E_{\text {hydratation }}\right)$, Refractivity and Polarizability. Molar volume, Molar depth, Hydrophilic lipophilic balance (HLB), Solubility parameter $\left(S_{p}\right)$, Hansen dispersion, Hansen polarity, Hydrogen bond acceptor (HBAcc), Hydrogen bond donor (HBD), Parachor, Kappa 2, Total e state, Water solubility, Connectivity indices, Valence indices, $\log P$ Crippen, Surface tension in water $\left(\mathrm{ST}_{\mathrm{W}}\right)$, Hydrogen bond number (HBN), Hydrophilic surface area (HSA) and Polar surface area (PSA) were calculated by MMP Plus [19]. ChemDraw 8.0 was used to calculate $\log P$. Statistical calculations, variable selection routine and multiple linear regression analysis (MLR) were performed by NCSS 2004 software package [20]. We carried out multivariate variable selection to select descriptors for MLR. The reduced collection of descriptors was used as the input for final MLR analysis. The quality criteria of the fit in MLR analysis were squared correlation coefficients $\left(r^{2}\right)$, cross-validated coefficient $\left(r_{c v}^{2}\right)$, the mean square error (MSE) and Fischer significance value $(F)$. The prediction performance was validated using a "leave-one-out" cross validation method. The cross-validated $r_{c v}^{2}$ values reflect the overall predictive ability of the model defined as (SSY-PRESS)/SSY. PRESS is predicted residual error sum of squares and SSY is the sum of the squared deviations of the dependent variable values from their mean. The significance level of the performed calculations was above $95 \%$. $R_{M}$ values were calculated by use of the Bate-Smith and Westall equation [21].

\section{Results and Discussion}

Structures of the investigated antipsychotics are shown in Figure 1 while their names, IUPAC names and molecular formula are listed in Table 1.

The retention parameters $\left(R_{F}\right.$ and $\left.R_{M}\right)$ of observed antipsychotics were determined at several compositions of the three different binary solvent systems composed of organic modifier and water: methanol-water, acetonewater and tetrahydrofuran-water. The investigated compounds, regardless on differences in their structure, showed some regularity in chromatographic behavior under applied chromatographic condition. Hydrophobic interactions dominated in reversed-phase thin layer chromatography. The most nonpolar compound has the highest retention in all applied mobile-phases. Also, regular retention behavior was observed, i.e. retention decreased regularly with increasing concentration of organic modifier in the mobile phase.

The linear relationship between the $R_{M}$ values and the concentration of the organic modifier in the mobile phase $(\varphi)$, expressed by Equation (1). $R_{M}^{0}$ is lipophilicity parameter and $\mathrm{m}$ is the slope and represents the hydrophobic surface area. Lipophilicity, measured as $R_{M}^{0}$, represents the relative affinity of different compounds for the non-aqueous environment in the biological system. $R_{M}^{0}$ is the value of $R_{M}$ in pure water, and therefore it 
could reflect the dependence of the hydrophobic properties of investigated compound on its structure.

The slope (m) and intercept $\left(R_{M}^{0}\right)$ values, and the statistical data (correlation coefficient $(r)$ and standard deviation (s)) for each binary system are listed in Table 2.

The chromatographically obtained lipophilicity parameter, $R_{M}^{0}$, is in agreement with structures of the investigated antipsychotics. The results from Table 2 show difference between the $R_{M}^{0}$ of investigated compounds. For all investigated compounds, the $R_{M}^{0}$ values are highest in methanol, which has the lowest elution strength among all the organic modifiers applied. Taking into account the observed retention, it can be concluded that compounds 7 and 4 exhibit stronger retention compared to 1 and 3. Retention of the compounds 7 and 4 is increased due to delocalization of electrons of substituents along the rings. Based on $R_{M}$ values (Table 2) the tested compounds are in accordance with the increasing lipophilicity (for the methanol and acetone as organic modifiers) described as follows: $1<3<2<5<6<4<7$. This sequence is different when tetrahydrofuran applied as organic modifier. Also, compound 1 has a higher mobility and lower $R_{M}^{0}$ values, in all applied mobile

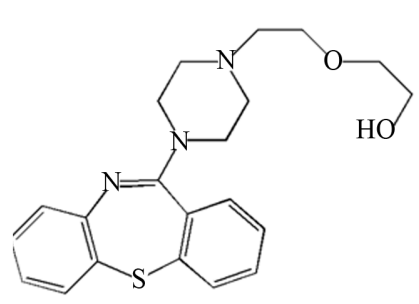

1<smiles>CN1CCN(C2=Nc3cc(Cl)ccc3Nc3ccccc32)CC1</smiles>

2<smiles>CCN1CCCC1NC(=O)C1=CC(C(=O)O)C(N)C=C1OC</smiles>

3<smiles>O=C1CCc2ccc(OCCCCN3CCN(c4cccc(Cl)c4Cl)CC3)cc2N1</smiles>

4<smiles>Cc1cc2c(s1)Nc1ccccc1N=C2N1CCN(C)CC1</smiles>

5

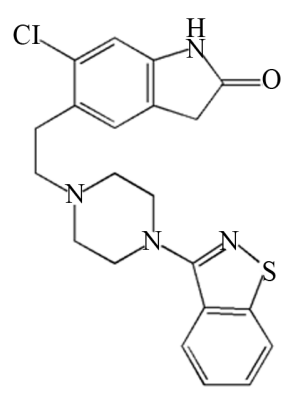

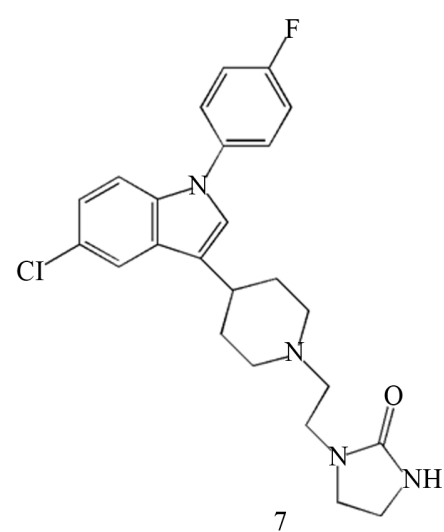

Figure 1. Structures of the investigated antipsychotics.

Table 1. IUPAC names, and molecular formula of investigated antypsichotics.

\begin{tabular}{|c|c|c|c|}
\hline No & Name & IUPAC name & Molecular formula \\
\hline 1 & Seroquel & 2-(2-(4-dibenzo[b,f][1] [4]tiazepin-11-il-1-piperazinil)etoksi)ethanol & $\mathrm{C}_{21} \mathrm{H}_{25} \mathrm{~N}_{3} \mathrm{O}_{2} \mathrm{~S}$ \\
\hline 2 & Leponex & 8-hloro-11-(4-metilpiperazin-1-il)-5H-dibenzo[b,e][1] [4]diazepin & $\mathrm{C}_{18} \mathrm{H}_{19} \mathrm{ClN}_{4}$ \\
\hline 3 & Solian & 4-amino-N-[(1-etilpirolidin-2-il)metil]-5-etilsulfonil-2-metoksi-benzamid & $\mathrm{C}_{17} \mathrm{H}_{27} \mathrm{~N}_{3} \mathrm{O}_{4} \mathrm{~S}$ \\
\hline 4 & Abilify & 74-[4-(2,3-dihlorofenil)piperazin-1-il]butoksi3,4-dihidrohinolin-2(1H)-on & $\mathrm{C}_{23} \mathrm{H}_{27} \mathrm{Cl}_{2} \mathrm{~N}_{3} \mathrm{O}_{2}$ \\
\hline 5 & Zalasta & 2-metil-4-(4-metil-1-piperazinil)-10H-tio[2,3-b] [1] [5]benzodiazepin & $\mathrm{C}_{17} \mathrm{H}_{20} \mathrm{~N}_{4} \mathrm{~S}$ \\
\hline 6 & Zeldox & 5-[2-[4-(1,2-benzizotiazol-3-il)-1-piperazinil]etil]-6-hloro-1,3-dihidro-2H-indol-2-on & $\mathrm{C}_{21} \mathrm{H}_{21} \mathrm{ClN}_{4} \mathrm{OS}$ \\
\hline 7 & Serdolect & 1-[2-[4-[5-hloro-1-(4-fluorofenil)-indol-3-il]-1-piperazil]etil] imidazolidin-2-on & $\mathrm{C}_{24} \mathrm{H}_{26} \mathrm{ClFN}_{4} \mathrm{O}$ \\
\hline
\end{tabular}


Table 2. Lipophilicity parameter and regression data.

\begin{tabular}{|c|c|c|c|c|c|c|c|c|c|c|c|c|}
\hline \multirow{2}{*}{ No. } & \multicolumn{4}{|c|}{ Acetone-water } & \multicolumn{4}{|c|}{ Methanol-water } & \multicolumn{4}{|c|}{ Tetrahydrofuran-water } \\
\hline & $R_{M}^{0}$ & $-m$ & $-r$ & $s$ & $R_{M}^{0}$ & $-\mathrm{m}$ & $-r$ & $S$ & $R_{M}^{0}$ & $-\mathrm{m}$ & $-r$ & $s$ \\
\hline 1 & $\begin{array}{c}1.859 \\
( \pm 0.127)\end{array}$ & $\begin{array}{c}2.824 \\
( \pm 0.158)\end{array}$ & 0.995 & 0.045 & $\begin{array}{c}2.033 \\
( \pm 0.146)\end{array}$ & $\begin{array}{c}2.371 \\
( \pm 0.167)\end{array}$ & 0.993 & 0.04 & $\begin{array}{c}1.440 \\
( \pm 0.199)\end{array}$ & $\begin{array}{c}2.369 \\
( \pm 0.269)\end{array}$ & 0.975 & 0.065 \\
\hline 2 & $\begin{array}{c}2.247 \\
( \pm 0.143)\end{array}$ & $\begin{array}{c}3.145 \\
( \pm 0.180)\end{array}$ & 0.995 & 0.051 & $\begin{array}{c}3.073 \\
( \pm 0.108)\end{array}$ & $\begin{array}{c}3.364 \\
( \pm 0.123)\end{array}$ & 0.998 & 0.03 & $\begin{array}{c}2.213 \\
( \pm 0.181)\end{array}$ & $\begin{array}{c}3.423 \\
( \pm 0.244)\end{array}$ & 0.989 & 0.059 \\
\hline 3 & $\begin{array}{c}1.928 \\
( \pm 0.142)\end{array}$ & $\begin{array}{c}2.461 \\
( \pm 0.177)\end{array}$ & 0.992 & 0.051 & $\begin{array}{c}2.973 \\
( \pm 0.143)\end{array}$ & $\begin{array}{c}3.164 \\
( \pm 0.163)\end{array}$ & 0.996 & 0.039 & $\begin{array}{c}2.128 \\
( \pm 0.100)\end{array}$ & $\begin{array}{c}3.186 \\
( \pm 0.135)\end{array}$ & 0.996 & 0.033 \\
\hline 4 & $\begin{array}{c}3.091 \\
( \pm 0.243)\end{array}$ & $\begin{array}{c}3.822 \\
( \pm 0.303)\end{array}$ & 0.99 & 0.087 & $\begin{array}{c}3.873 \\
( \pm 0.174)\end{array}$ & $\begin{array}{c}3.805 \\
( \pm 0.174)\end{array}$ & 0.996 & 0.048 & $\begin{array}{c}2.100 \\
( \pm 0.392)\end{array}$ & $\begin{array}{c}3.069 \\
( \pm 0.529)\end{array}$ & 0.945 & 0.128 \\
\hline 5 & $\begin{array}{c}2.613 \\
( \pm 0.196)\end{array}$ & $\begin{array}{c}3.149 \\
( \pm 0.244)\end{array}$ & 0.991 & 0.07 & $\begin{array}{c}3.323 \\
( \pm 0.140)\end{array}$ & $\begin{array}{c}3.371 \\
( \pm 0.160)\end{array}$ & 0.997 & 0.038 & $\begin{array}{c}2.347 \\
( \pm 0.195)\end{array}$ & $\begin{array}{c}3.411 \\
( \pm 0.264)\end{array}$ & 0.988 & 0.064 \\
\hline 6 & $\begin{array}{c}2.817 \\
( \pm 0.042)\end{array}$ & $\begin{array}{c}3.721 \\
( \pm 0.053)\end{array}$ & 0.999 & 0.015 & $\begin{array}{c}3.803 \\
( \pm 0.185)\end{array}$ & $\begin{array}{c}3.950 \\
( \pm 0.211)\end{array}$ & 0.996 & 0.051 & $\begin{array}{c}2.595 \\
( \pm 0.204)\end{array}$ & $\begin{array}{c}3.800 \\
( \pm 0.276)\end{array}$ & 0.989 & 0.067 \\
\hline 7 & $\begin{array}{c}3.587 \\
( \pm 0.127)\end{array}$ & $\begin{array}{c}4.368 \\
( \pm 0.159)\end{array}$ & 0.998 & 0.045 & $\begin{array}{c}4.878 \\
( \pm 0.208)\end{array}$ & $\begin{array}{c}4.829 \\
( \pm 0.238)\end{array}$ & 0.996 & 0.057 & $\begin{array}{c}2.263 \\
( \pm 0.258)\end{array}$ & $\begin{array}{c}3.189 \\
( \pm 0.349)\end{array}$ & 0.977 & 0.084 \\
\hline
\end{tabular}

phases, as most polar compound. Lipophilicity parameter of compound 1 is lowest, when as organic modifier was applied tetrahydrofuran, which is in accordance with polarity of this organic solvent (4.0) in comparison with methanol and acetone (5.1) [22]. High correlation was obtained between the intercept $R_{M}^{0}$ and the slopes, $\mathrm{m}$, values (Table 3 ).

The $\mathrm{m}$ values are specific hydrophobic surface of the observed compound while the $R_{M}^{0}$ is lipophilicity parameter. High correlation coefficients indicate that the substances investigated could be regarded as a homologous series [23].

Also, the chromatographically determined lipophilicity parameter values with different organic modifier were correlated. The equations of these linear relationships are:

$$
\begin{gathered}
R_{M \text { acetone }}^{0}=0.282\left(R_{M \text { methanol }}^{0}\right)+0.678 \quad\left(r^{2}=0.950 ; s=0.215 ; P=0.001\right) \\
R_{M \text { acetone }}^{0}=0.592\left(R_{M \text { THF }}^{0}\right)+0.928 \quad\left(r^{2}=0.524 ; s=0.589 ; P=0.228\right) \\
R_{M \text { methanol }}^{0}=-0.167\left(R_{M \text { THF }}^{0}\right)+1.666 \quad\left(r^{2}=0.668 ; s=0.724 ; P=0.101\right)
\end{gathered}
$$

These differences are most probably a consequence of the different chemical natures of the three organic modifier (such as polarity as well as elution power) and indicates that the values basicaly reflect the some molecular propeties of the solute in the mobile phases used.

In order to established quantitative-structure models, we used the calculated molecular descriptors as a quantitative measure of individual structural features. Due to the collinearity problem in MLR analysis, the collinear descriptors $(r>0.9)$ can be removed before model development, by applying the heuristic method [24]. A correlation check for the descriptors was performed. Established QSAR models for different organic modifiers in mobile phase are shown in Table 4.

This is in accordance with experimentally obtained retention parameters. Based on statistically parameters we checked the robustness of established QSAR models. The statistically best model was obtained when organic modifier was acetone (model 1, Table 4). It is well known that the smaller PRESS is, the better the predictability of the model [25]. If PRESS is smaller than SSY the model predict is better than chance and can be considered to be statistically significant. In a reasonable QSAR model, PRESS/SSY should be smaller than 0.4 (model 1 and 2, Table 4). Obtained value of PRESS/SSY ratio is smaller than 0.1 indicates an excellent established model (model 1, Table 4) [26]. Also, QSAR model 1 shows a high degree of correlation between experimentally obtained and predicted parameters of retention, $R_{M}$ (Figure 2).

Established model 1 gives us the possibility to gain insight into factors responsible for the retention as well as lipophilicity of the investigated set of the compounds. The results obtained indicate that the most relevant descriptors influencing lipophilicity parameters are: Energy of the highest occupied molecular orbital, Energy of 
Table 3. Correlation coefficients for correlation between the intercept $R_{M}^{0}$ and the slopes ( $m$ ) values.

\begin{tabular}{cc}
\hline Modifier & $r^{2}$ \\
\hline Acetone & 0.932 \\
Methanol & 0.993 \\
Tetrahydrofuran & 0.977 \\
\hline
\end{tabular}

Table 4. Regression QSAR models obtained for three different mobile phase modifiers.

\begin{tabular}{|c|c|c|c|c|c|c|c|c|}
\hline Model & Modifier & Equation & $r^{2}$ & $\mathrm{~F}$ & MSE & $r_{c v}^{2}$ & PRESS & PRESS/SSY \\
\hline 1 & Acetone & $\begin{array}{c}R_{M}^{0}=5.405( \pm 1.761)-0.067( \pm 0.058) \cdot S_{p}+ \\
6.718( \pm 1.452) \cdot E_{\mathrm{HOMO}}+24.180( \pm 2.286) \cdot E_{\mathrm{LUMO}}\end{array}$ & 0.976 & 40.899 & 0.002 & 0.922 & 0.187 & 0.078 \\
\hline 2 & Methanol & $\begin{array}{c}R_{M}^{0}=5.638( \pm 3.502)-0.069( \pm 0.115) \cdot S_{p}+ \\
6.467( \pm 2.888) \cdot E_{\mathrm{HOMO}}+33.751( \pm 4.545) \cdot E_{\mathrm{LUMO}}\end{array}$ & 0.952 & 19.995 & 0.008 & 0.606 & 1.863 & 0.394 \\
\hline 3 & Tetrahydrofuran & $\begin{array}{l}R_{M}^{0}=-0.148( \pm 3.116)+0.113( \pm 0.110) \cdot S_{p}+ \\
8.622( \pm 4.302) \cdot E_{\text {LUMO }}-0.108( \pm 0.064) \cdot \mathrm{HSA}\end{array}$ & 0.710 & 2.444 & 0.007 & 0.015 & 1.640 & 2.153 \\
\hline
\end{tabular}

$S_{p}$-Solubility parameter; $E_{\mathrm{HOMO}}$-Energy of the highest occupied molecular orbital; $E_{\mathrm{Lumo}}$-Energy of the lowest unoccupied molecular orbital; HSAHydrophilic surface area; $r^{2}$-correlation coefficient; F-Fischer significance value; MSE-mean square error; $r_{c v}^{2}$-cross-validated coefficient; PRESSpredicted residual error sum of squares; SSY-sum of the squared deviations.

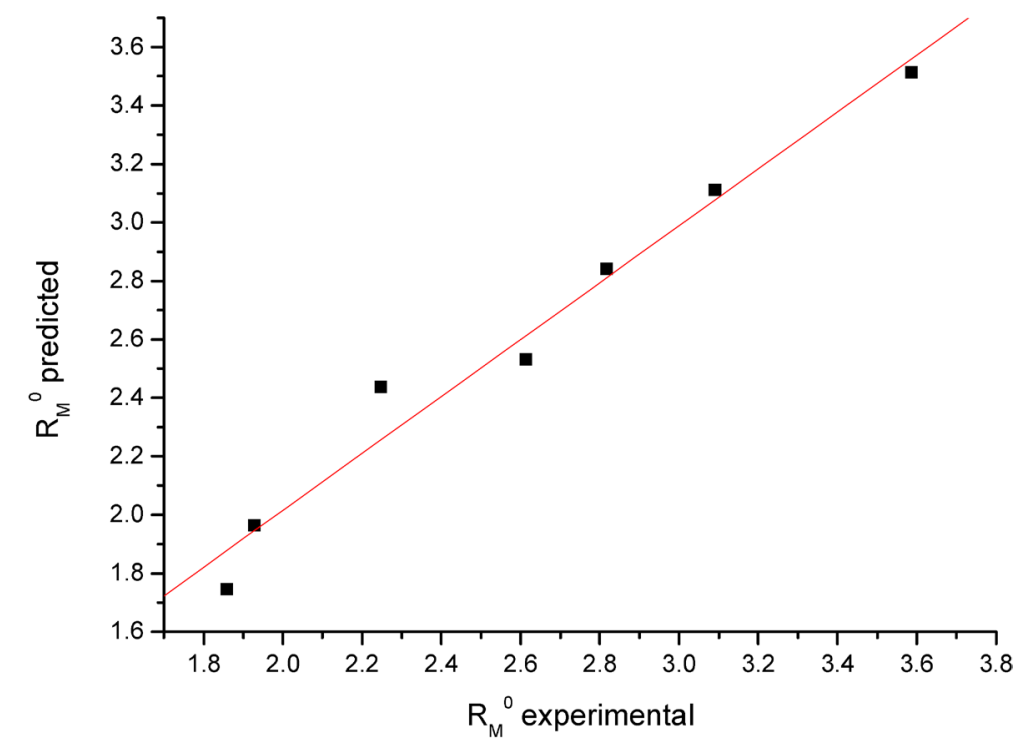

Figure 2. Predicted $R_{M}^{0}$ estimated by MLR versus experimental $R_{M}^{0} \quad$ (model 1).

the lowest unoccupied molecular orbital, and Solubility parameter. These descriptors can be accounted for the structural features responsible for chromatographic behavior as well as chromatographically determined lipophilicity parameter of investigated compounds. Lipophilicity parameter of investigated compounds increases with increasing $E_{\mathrm{HOMO}}$ and $E_{\mathrm{LUMO}}$ descriptors and decrease with increasing of solubility parameter. The order of significance of the descriptors is: $E_{\mathrm{LUMO}}>E_{\mathrm{HOMO}}>S p$. It is obviously that $E_{\mathrm{LUMO}}$ has the highest significance impact in comparison with $E_{\mathrm{HOMO}}$ and $S p$. The $E_{\mathrm{LUMO}}$ is the property of electronic structure and represents the electron affinity of a molecule or its reactivity as an electrophile. Good electrophiles are those were the $E_{\mathrm{Lumo}}$ is "low-lying" [27]. The presence of $E_{\mathrm{LUMO}}$ in this model suggests that the higher this energy is, the weaker are the interactions of the compounds with mobile phases, and also higher values of $R_{M}^{0}$ were observed. This is in ac- 
cordance with chromatographic behavior of these compounds. A higher $E_{\text {Номо }}$ suggests higher affinity of the molecule to react as a nucleophile. Therefore, the compounds with high values of $E_{\text {номо }}$ shows the highest retention under applied reversed-phase chromatographic conditions as well as highest $R_{M}^{0}$ as can be seen from established model 1 (Table 4). Solubility parameter indicate that the stronger the intermolecular interactions between molecules and mobile phase are, the analytes are less retained on the stationary phase and lower $R_{M}$ as well as $R_{M}^{0}$ are obtained.

Therefore, from Table 4 it is evident that the same molecular descriptors describe lipophilicity in models 1 and 2 regardless on applied organic modifiers. This is probably a consequence of the different eluotropic strength of applied organic modifiers. Model 2 is less statistically significant than model 1, probably due to ability of molecules of methanol to form monolayer at the surface of stationary phase [28]. The influence of applied organic modifier is obvious when tetrahydrofuran is in the mobile phase (model 3, Table 4). In this model the opposite influence of Solubility parameter was obtained and Hydrophilic surface area occurs as relevant molecular descriptor. This is in accordance with mechanisms in reversed-phase thin-layer chromatography considering properties of applied organic modifiers in eluotropic series based on polarity parameters [22].

\section{Conclusion}

Quantitative structure-activity relationship studies have been performed to correlate the molecular characteristics of observed compounds with their retention as well as with their chromatographically determinated lipophilicity parameters. RP TLC proved to be a reliable and accurate method of describing the lipophilic nature of observed antipsychotics. Obtained results are in agreement with polarity of applied organic modifiers as well as structure of investigated compounds. In addition, we used molecular descriptors to establish QSAR models for all applied mobile phases. Established QSAR model for acetone as organic modifier (model 1) is excellent. For this model PRESS/SSY value is smaller than 0.1. This study provides good information about pharmacologically important physico-chemical parameters of observed antipsychotics relevant to variations in molecular lipophilicity and chromatographic behavior. A very advantageous feature of established models is that it allows us to understand chromatographic behavior of novel, not yet synthesized compounds, solely from their structural descriptors, and to estimate lipophilicity for similar compounds. These QSAR models could help multi-target novel antipsychotic compound design.

\section{Acknowledgements}

This work was performed within the framework of the research project No 172017 supported by the Ministry of Education, Science and Technological development of Serbia.

\section{References}

[1] Sarbu, C., Casoni, D., Darabantu, M. and Maiereanu, C. (2004) Quantitative Structure-Retention and Retention-Activity Relationships of Some 1,3-Oxazolidine Systems by RP-HPTLC and PCA. Journal of Pharmaceutical and Biomedical Analysis, 35, 213-219. http://dx.doi.org/10.1016/j.jpba.2004.01.002

[2] Ghasemi, J. and Saaidpour, S. (2009) QSRR Prediction of the Chromatographic Retention Behavior of Painkiller Drugs. Journal of Chromatographic Science, 47, 156-163. http://dx.doi.org/10.1093/chromsci/47.2.156

[3] Durcekova, T., Boronova, K., Mocak, J., Lehotay, J. and Cizmarik, J. (2012) QSRR Models for Potential Local Anaesthetic Drugs Using High Performance Liquid Chromatography. Journal of Pharmaceutical and Biomedical Analysis, 59, 209-216. http://dx.doi.org/10.1016/j.jpba.2011.09.035

[4] Nantasenamat, C., Isarankura-Na-Ayudhya, C., Naenna, T. and Prachayasittikul, V. (2009) A Partical Overview of Quantitative Structure-Activity. EXCLI Journal, 8, 74-88.

[5] McElroy, S.L., Keck Jr., P.E. and Strakowski, S.M. (1996) Mania, Psychosis, and Antipsychotics. Journal of Clininical Psychiatic, 57, 14-26.

[6] Harrison, P.J. (1999) The Neuropathological Effects of Antypsychotic Drugs. Schizophrenia Research, 40, 87-99. http://dx.doi.org/10.1016/S0920-9964(99)00065-1

[7] Bleakley, S., Olofinjana, O. and Taylor, D. (2007) Which Antipsychotics Would Mental Health Professionals Take Themselves? Psychiatric Bulletin, 31, 94-96. http://dx.doi.org/10.1192/pb.bp.106.012955

[8] Bhosale, S.H., Kanhed, A.M., Dash, R.C., Suryawanshi, M.R. and Mahadik, K.R. (2014) Design, Synthesis, Pharmacological Evaluation and Computational Studies of 1-(Biphenyl-4-yl)-2-[4-(substituted phenyl)-piperazin-1-yl] Etha- 
nones as Potential Antipsychotics. European Journal of Medicinal Chemistry, 74, 358-365. http://dx.doi.org/10.1016/j.ejmech.2013.12.043

[9] Lipinski, C.A. (2000) Drug-Like Properties and the Causes of Poor Solubility and Poor Permeability. Journal of Pharmacolical and Toxicological Methods, 44, 235-249. http://dx.doi.org/10.1016/S1056-8719(00)00107-6

[10] Löscher, W. (2005) Blood-Brain Barrier Active Efflux Transporters: ATP-Binding Cassette Gene Family. NeuroRX, 2 , 86-98. http://dx.doi.org/10.1602/neurorx.2.1.86

[11] Varshney, A., Sen, P., Ahmad, E., Rehan, M., Subbarao, N. and Khan, R.H. (2010) Ligand Binding Strategies of Human Serum Albumin: How Can the Cargo Be Utilized? Chirality, 22, 77-87. http://dx.doi.org/10.1002/chir.20709

[12] Sethi, B., Soni, M., Kumar, S., Gupta, G.D., Mishra, S. and Singh, R. (2010) Lipophilicity Measurement through Newer Techniques. Journal of Pharmacy Research, 3, 345-351.

[13] Slawik, T. and Paw, B. (2003) RP-TLC Determination of the Lipophilicity of 1,2-Benzisothiazol-3(2H)-one Derivatives Substituted in the Heterocyclic Ring. Journal of Planar Chromatography Modern TLC, 16, 442-446. http://dx.doi.org/10.1556/JPC.16.2003.6.7

[14] Kostecka, M., Niewiadomy, A. and Czeczko, R. (2005) Evaluation of N-Substituted 2,4-Dihydroxyphenylthioamide Fungicide Lipophilicity Using the Chromatographic Techniques HPLC and HPTLC. Chromatographia, 62, 121-126. http://dx.doi.org/10.1365/s10337-005-0597-5

[15] Cserhati, T., Forgacs, E. and Hajos, G. (1998) Determination of the Lipophilicity of Fused-Ring Nitrogen-Heterocycles by Reversed-Phase Thin Layer Chromatography-The Effect of pH. Journal of Planar Chromatography Modern TLC, 11, 64-69.

[16] Baosic, R., Radojevic, A., Radulovic, M., Miletic, S., Natic, M. and Tesic, Z. (2008) Relationships between Structure, Retention and Biological Activity of Some Schiff Base Ligands and Their Complexes. Biomedical Chromatography, 22, 379-386. http://dx.doi.org/10.1002/bmc.943

[17] Brzezinska, E. and Koska, F. (2006) A Structure-Activity Relationship Study of Compounds with Antihistamine Activity. Biomedical Chromatography, 20, 1004-1016. http://dx.doi.org/10.1002/bmc.621

[18] Kiralj, R. and Ferreira, M. (2009) Basic Validation Procedures for Regression Models in QSAR and QSPR Studies: Theory and Application. Journal of Brazilian Chemical Society, 20, 770-787. http://dx.doi.org/10.1590/S0103-50532009000400021

[19] http://www.norgwyn.com/mmpplus.html

[20] Hintze, J., NCSS and PASS (2001) Number Cruncher Statistical Systems. Kaysville. www.ncss.com

[21] Bate-Smith, E.C. and Westall, R.G. (1950) RPTLC Determination of the Lipophilicity of 1,2-Benzisothiazol-3(2H)one Derivatives Substituted in the Heterocyclic Ring. Biochimica et Biophysica Acta, 4, 427-440. http://dx.doi.org/10.1016/0006-3002(50)90049-7

[22] Snyder, L.R. (1978) Classification of the Solvent Properties of Common Liquids. Chromatography Science, 16, 223234. http://dx.doi.org/10.1093/chromsci/16.6.223

[23] Tetko, I.V. and Tachuk, V. (2002) Prediction of n-Octanol/Water Partition Coefficients from PHYSPROP Database Using Artificial Neural Networks and E-State Indices. Journal Chemical Information and Communication Science, 42, 1136-1145.

[24] Ma, W., Luan, F., Zhang, H., Zhang, X., Liu, M. and Hu, Z. (2006) Quantitative Structure-Property Relationships for Pesticides in Biopartitioning Micellar Chromatography. Journal of Chromatographia A, 1113, 140-147. http://dx.doi.org/10.1016/j.chroma.2006.01.136

[25] Dabić, D., Natić, M., Džambaski, Z., Marković, R., Milojković-Opsenica, D. and Tešić, Ž. (2011) Quantitative Structure-Retention Relationship of New N-Substituted 2-Alkylidene-4-oxothiazolidines. Journal of Separation Science, 34, 2397-2404.

[26] H. Van de Waterbeemd (1995) Chemometric Methods in Molecular Design. Wiley-VCH, Weinheim. http://dx.doi.org/10.1002/9783527615452

[27] Suzuki, T., Timofei, S., Iuoras, B., Uray, G., Verdino, P. and Fabian, W. (2001) Quantitative Structure-Enantioselective Retention Relationships for Chromatographic Separation of Arylalkylcarbinols on Pirkle Type Chiral Stationary Phases. Journal of Chromatographia A, 922, 13-23.

[28] Tosti, T., Natić, M., Dabić, D., Milić, D., Milojković-Opsenica, D. and Tešić, Ž. (2012) Structure-Retention Relationship Study of Polyoxygenated Steroids. Journal of Separation Science, 35, 2693-2698. http://dx.doi.org/10.1002/jssc.201200423 